\title{
Using $Q R$ codes to aid accessibility in a museum
}

\section{Article}

Accepted Version

\section{Postprint}

Haworth, A. and Williams, P. (2012) Using QR codes to aid accessibility in a museum. Journal of Assistive Technologies, 6 (4). pp. 285-291. ISSN 2042-8723 doi:

https://doi.org/10.1108/17549451211285771 Available at https://centaur.reading.ac.uk/33754/

It is advisable to refer to the publisher's version if you intend to cite from the work. See Guidance on citing.

To link to this article DOI: http://dx.doi.org/10.1108/17549451211285771

Publisher: Emerald

All outputs in CentAUR are protected by Intellectual Property Rights law, including copyright law. Copyright and IPR is retained by the creators or other copyright holders. Terms and conditions for use of this material are defined in the End User Agreement.

\section{www.reading.ac.uk/centaur}

\section{CentAUR}

Central Archive at the University of Reading

Reading's research outputs online 
Journal of Assistive Technologies 2012 vol 6, iss: 4

\section{Using QR codes to aid accessibility in a museum}

Annette Haworth, Access-ability Communications Technology

Peter Williams, Department of Information Studies, University College London

\section{Introduction}

Although it has long been recognised that electronic media may greatly facilitate access to information (e.g. Abbott, 2001, 2008; Florian, 2004; Adam and Tatnall, 2008), material can remain inaccessible to those with limited physical or cognitive abilities or poor ICT skills. However, the range of consumer technology with the potential to enable access is increasing rapidly (Baxter et al, 2012). Smartphones and tablets (Doughty, 2011) together with the associated rise of non-text interfaces offer opportunities to further break-down accessibility barriers.

This mobile technology has particular interest for museums seeking to broaden visitorengagement (Proctor, 2012; Koushik et al, 2010). Encouraged by this, a small volunteer-run charity, Access-ability Communications Technology, is seeking low-cost ways that the technology might enhance museum accessibility through its iMuse Programme. Its first project ran from January-July 2012, creating short trails around the Museum of English Rural Life, Reading, UK. Symbolised labels enabled visitors to learn about museum objects by scanning QR codes using an Apple iPad provided by the Charity or their own smartphone. Reading Borough Council and the Vodafone Foundation funded additional IT support. The RSA Fellowship Catalyst scheme funded help from museum-learning and web-accessibility experts.

This article considers the accessibility issues that were raised, outlining the technologies used and reporting on observations of visitors' ability to use the system.

\section{Method}

Activities were devised which involved visitors finding out about four to six museum objects, each with a QR code and symbolised text. Visitors scanned the QR codes using an iPad or smartphone which showed more information about the object, in the form of text, pictures, video or audio. Project-team members acted as participant-observers, engaging with visitors and noting how they used the system (Figure 1). Of particular interest were any difficulties with scanning the QR codes. Some feedback was gathered through informal discussion with visitors as they completed an activity.

Additional observations were made of visitors following part of a trail where team members did not have a participatory role, and feedback was gathered from museum staff being introduced to a variety of label design and from two 16-year olds with special needs who 
took assisted trails. Observations from each activity influenced both the label design and the way the iPad was set-up for subsequent activities.

\begin{tabular}{|c|c|c|c|c|}
\hline \multirow{2}{*}{$\begin{array}{l}\text { Museum } \\
\text { event }\end{array}$} & \multirow{2}{*}{ Activity name } & \multicolumn{2}{|c|}{ Visitors } & \multirow{2}{*}{ Observers' role within the activity } \\
\hline & & Adult & Child & \\
\hline Toddler time & Vehicle Hunt & 8 & 12 & Museum guide \\
\hline $\begin{array}{l}\text { Spring half- } \\
\text { term }\end{array}$ & $\begin{array}{c}\text { Cheese Mystery } \\
\text { Quest }\end{array}$ & 85 & 134 & $\begin{array}{l}\text { 'Lab technician' within the story (which was devised } \\
\text { as the basis for the structure of the quest) }\end{array}$ \\
\hline $\begin{array}{l}\text { School } \\
\text { holidays }\end{array}$ & $\begin{array}{l}\text { Fire-engine } \\
\text { Mystery Quest }\end{array}$ & 24 & 36 & $\begin{array}{l}\text { 'Lab technician' within the story (which was devised } \\
\text { as the basis for the structure of the quest) }\end{array}$ \\
\hline School visit & & 10 & 44 & Museum guide \\
\hline $\begin{array}{l}\text { General } \\
\text { opening }\end{array}$ & $\begin{array}{l}\text { Berkshire Farmer } \\
\text { Trail }\end{array}$ & 10 & 9 & $\begin{array}{l}\text { Guide on assisted trail or none (while observing } \\
\text { visitors' independent use of the system). }\end{array}$ \\
\hline
\end{tabular}

Figure 1: Participation in museum activities

\section{Technology}

Choice of technology was influenced by the iMuse Programme's guidelines:

Concentrate on what might be practical for modest-sized museums; experiment quickly/iteratively (fail fast, fail often); test in the field and with 'real' users; aim for sustainability by leveraging visitors' own equipment, using freely available systems; design so the least able are able to take part; link dynamically if possible to existing museum content.

Native app development (i.e. apps developed specifically for use on a particular platform or device) was ruled-out on cost grounds (Forbes, 2011). There is much interest in the heritage world in a potential alternative - the mobile-web coupled with QR codes ('2D-barcodes') (e.g. van Zeggeren, 2011). QR codes are free to create and can be scanned with a mobile device. They work by taking the browser to an encoded URL, such as to a museum's website.

If attached to the label for a museum object, the system 'knows' that the visitor is physically near that object and can show them object-specific content. In this mode QR codes have similar functionality to a key pressed on an audio-guide device. From an accessibility point of view, they have the additional advantage that the visitor cannot make a mistake by pressing the wrong key, nor do they have to be literate enough to interpret a text-sign to match with one on the screen. 
However the placing of QR codes can present museums with challenges. For some visitors, the physical difficulties of aligning the camera in a mobile device with a label mounted vertically on a wall can prove prohibitive. Additionally, on some devices the camera is offset from the centre making the lining-up process counter-intuitive. Finally, some devices may be too heavy or cumbersome to hold aloft and height differences mean the placing of codes can never be practical for all. After some experimentation, having the QR code on a label which the visitor could move was found to help the alignment process. 'Widgit' [i] symbols and other graphics were incorporated into labels where this was thought likely to aid understanding.

To be truly inclusive, a museum needs to provide a suitable, user-friendly device for those unable to bring their own. Smartphones present problems with screen-size so a tablet was selected, the iPad chosen because of its additional accessibility options such as ability to speak displayed text.

\section{The trials}

\section{Vehicle Hunt}

A4-sized labels were hung on museum objects which were examples of the depicted vehicles.

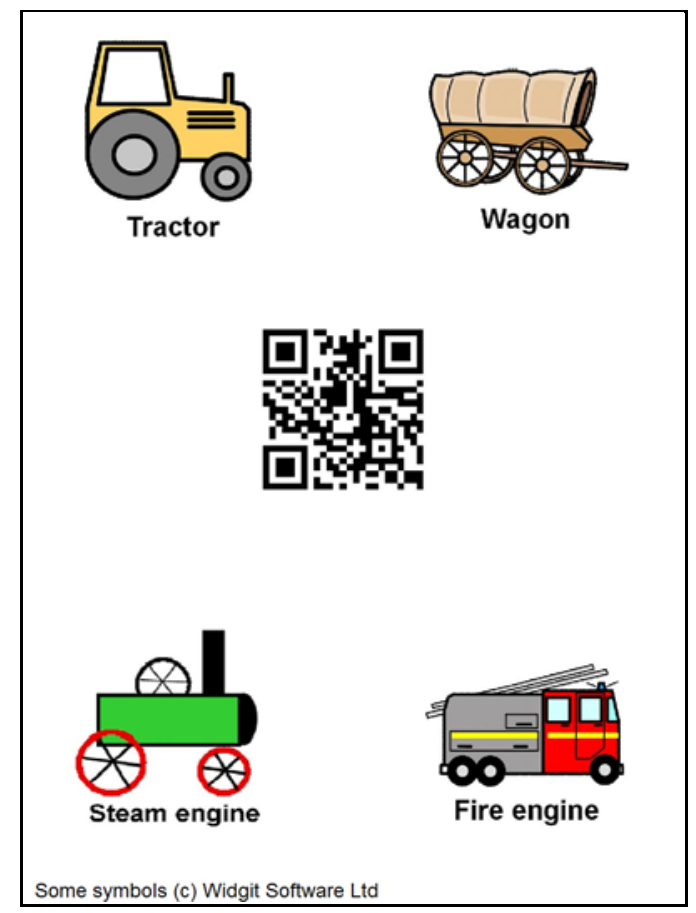

Figure 2: A4 label tied to a museum object for the Vehicle Hunt [i]

QR codes were scanned by the guide, causing the iPad to ask visitors to tap the relevant object's symbol. If correct, the iPad congratulated them and encouraged them to find another depicted object. 
Visitors showed strong recognition of the symbolised vehicles but the actual objects differed from them in shape and colour, resulting in some family-groups holding lively debate with their guide on which object was being viewed. Technology-based problems included: inability to 'tap' an icon on the screen sufficiently for it to react; low lighting-levels or shadows obscuring the code; alignment/height difficulties; poor network access.

\section{Quests}

These findings influenced design of Quest activities. 'Clues' (labels positioned near objects) contained a related symbol and QR code (Figure 3). Visitors had to find clues and bring them to a central point to be 'decoded'.

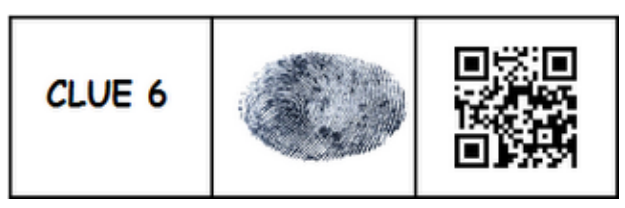

Figure 3: A clue in the Cheese Mystery quest

An iPad was mounted in a box which had a cut-out so that a label could be slipped underneath to be scanned, bringing up a further clue (Figure 4).

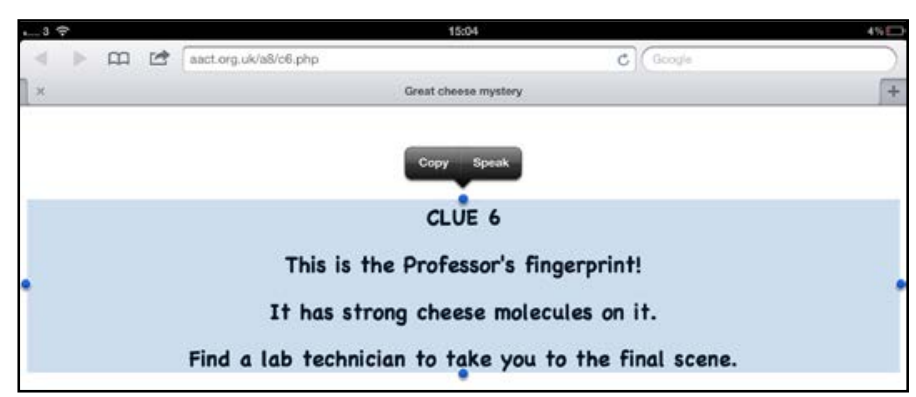

Figure 4: Screenshot from scanning the 'clue' label. The visitor has selected the iPad's inbuilt 'speak' accessibility option.

The iPad was fastened to a table with a cable which meant it could be moved to accommodate visitors, including use from a low wheelchair. Removing alignment and network difficulties, this system proved highly reliable. Children quickly understood how to work the 'decoder' and there was great enthusiasm. In the first quest, scanning a code gave a simple clue leading to the next object in text form. In the second, short video clips were introduced alongside.

\section{School visit}

These successes influenced the design of activities for a school visit. A museum mural was shown on box-mounted iPads with 'hot spot' areas outlined. Tapping a symbol caused the iPad to ask children to find a particular object, which when tapped in turn showed a video of it working. Children also enjoyed 'wearing' an iPad (hung around the neck) and scanning QR codes, bringing up sentences to be read. 
These experiences influenced the design of the system for a Trail based on a farmer's autobiography (Houghton, 1988, 1991). Some users found the iPad too heavy to carry so other methods were tried. While hanging an iPad around the neck had proved a safe and highly acceptable way for the school children, it proved uncomfortable for others and impossible for some with physical disabilities. To overcome this, a box-mounted iPad was fastened to a trolley and wheeled around the objects.

Various media were found to illustrate each object, for example a Youtube video showing the object being used, and short sections of the story were recorded. For each object, a set of labels with QR codes pointing to each medium was tied to the trolley. The back of the label was used also, to add a sentence about the object. There was room for both text and symbolisation (Figure 5 ).
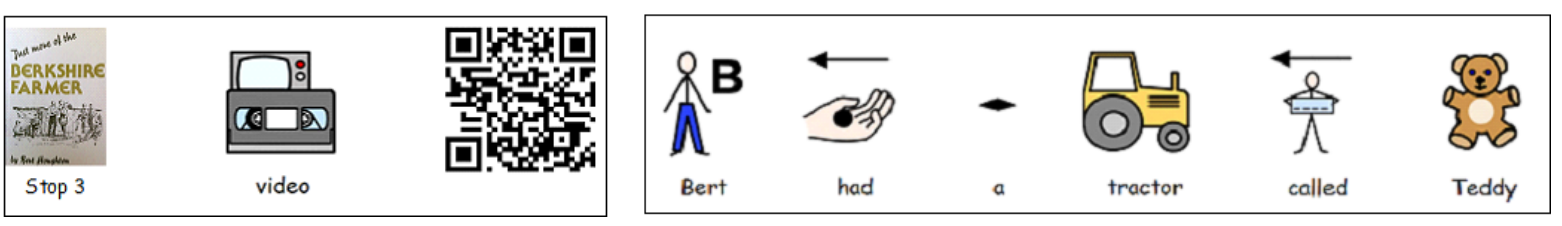

Figure 5: initial design of the two-sided object label with fully symbolised text

Accompanied by assistants, a young-person with special needs was asked to go round The Trail, choosing what to look at/listen to. They were reluctant to use the labels. Other iPadbased activities (drawing; taking photos and videos) were enjoyed and they returned to scan the labels. Video was always chosen first and replaying audio was often selected. Although the young person liked a realistic symbol on a label, they hated the symbolised sentences; as they explained, they themselves could 'speak'.

While the use of symbolised-text on museum labels does not seem to be widespread, the Eden Project (Abbott and Detheridge, 2012), which has fully symbolised sentences on display boards, has not reported visitor rejection so this reaction was unexpected. In response, the use of the less realistic, intermediary symbols was dropped and a photograph of the farmer substituted for the symbolised name. In a trial with a dozen museum staff and volunteers, labels symbolised in this way were selected over those which had only text.

Having one label per medium became too untidy and confusing for a multi-stop trail and the system was redesigned. Given the principle that all members of a group should be able to participate, layered information was presented within one trail rather than being segmented into different paths. The first layer consisted of a label tied to an object. This reassured the user that they were at the right place (photo of the object), on the right trail (graphic) and had the QR code, and even those who did not have technology could gather some information from the part-symbolised sentence. 

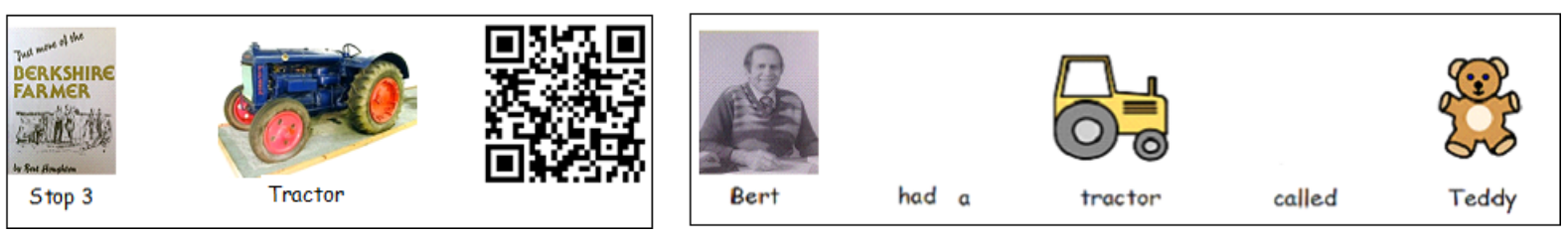

Figure 6: Two sides of a movable museum object label with only main words symbolised.

At the second layer, scanning the QR code displayed some basic information on the iPad - a small number of sentences about the farmer and the object - with options to select further content. The screen-layout was designed in the light of experiences of website usage by those with learning disabilities (Williams and Hanson-Baldauf, 2010; Williams and Nicholas, 2006).

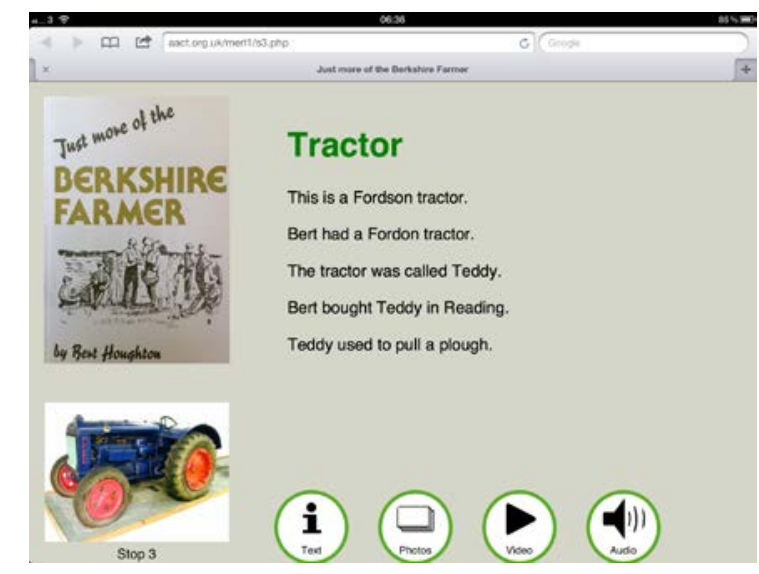

Figure 7: screenshot of the iPad on scanning the object label's QR code

Buttons allow the user to select information in a third layer. A feature of this, designed very much for people with low levels of literacy, is that it provides the option of choosing different media-types. Additional text, pictures, video and audio resources can be accessed. Regarding the latter, a museum's audio system was appreciated for allowing those with learning disabilities to repeatedly listen to an item independently [ii], and other work (e.g. Williams, 2012) has shown audio to be an acceptable text substitute. Repetition is enabled for all media, and in The Farmer's Trail, members of a learning-disabled visitor-group chose to view a video several times.

The trolley being wheeled by an assistant, another young person using a walking frame followed The Trail in this new form and scanned QR codes without difficulty. However, physical limitations meant the iPad could not be used as a mobile device. Related activity, collecting more material for The Trail, was undertaken using the young person's own smartphone, small enough to operate with one hand and with raised keys, though the iPad was appreciated for watching videos when sitting down.

Other visitors have also used their smartphones to scan the QR codes and family groups have been observed using the system unaided, with children in particular prepared to try the equipment to see what they can do, most choosing the video option. 


\section{Conclusions}

The enthusiastic response to the activities should encourage museums to further investigate the use of this technology to increase engagement and accessibility. However, this approach is not without cost (Burnette et al, 2011). Although the rise of visitor-owned mobile devices may release museums from providing much equipment, maintaining the information behind labels and keeping-up with technological changes are on-going processes.

Movable, symbolised labels with QR codes seem to offer potential for improving accessibility, but technical, physical, cultural and support issues will need consideration in individual museum environments. And, while a loaned iPad can aid accessibility, a visitor using their own mobile-device has the advantage that it will already be set-up with accessibility options of their choosing and will be familiar to them in other ways too (their own screen layout, for example).

The Charity plans to work with other museums to research these practicalities further.

\section{References}

Abbott C (2001) ICT: changing education Routledge, London, UK

Abbott C (2008) "E-inclusion: Learning Difficulties and Digital Technologies" Bristol: Futurelab available at: http://archive.futurelab.org.uk/resources/documents/lit reviews/Learning Difficulties Review.pdf (accessed 6 August 2012)

Abbott, C. and Detheridge, C. (2012) “Access all areas: the use of symbols in public spaces" in Understanding and promoting access for people with learning difficulties: seeing the challenges and opportunities of risk, Routledge, Abingdon, Oxon, pp. 57-68

Adam T., Tatnall A. (2008) "Using ICT to improve the education of students with learning disabilities" in Kendall M., Samways B. (Eds.) Learning to Live in the Knowledge Society Boston: Springer 218 pp. 63-70

Baxter, S., Enderby, P., Judge, S. and Evans, P. (2012) "Barriers and facilitators to use of high technology augmentative and alternative communication devices: a systematic review and qualitative synthesis", International Journal of Language and Communication Disorders, 47(2), pp. 115-129

Burnette A., Cherry, R., Proctor, N., Samis, P. (2011) “Getting On (not Under) the Mobile 2.0 Bus: Emerging Issues in the Mobile Business Model" paper presented at Museums and the Web Conference (MW11), Philadelphia, PA, USA, 5-9 April 2011 available at: http://www.museumsandtheweb.com/mw2011/papers/getting on not under the mobile 20 bus (accessed 6 August 2012)

Chan S., Dearnley L. (2012) “Using QR codes, mobile apps and wifi tracking data to understand visitor behaviour in exhibitions", paper presented at Museums and the Web, 11-14 April 2012, San Diego, USA, available at:

http://www.museumsandtheweb.com/mw2012/programs/using ar codes mobile apps and wifi tracking (accessed 30 July 2012)

Doughty, K. (2011) "SPAs (smart phone applications) - a new form of assistive technology", Journal of Assistive Technologies, Vol. 5 No. 2, pp.88-94 
Florian, L. (2004), "Uses of technology that support pupils with special educational needs", in Florian, L. and Hegarty, J. (Eds.), ICT and Special Educational Needs: a Tool for Inclusion, Open University Press, Berkshire, pp. $7-20$

Forbes T. (2011) "Native or Not? Why a Mobile Web App Might be Right for Your Museum”, in Proctor N (Ed.), Mobile Apps for Museums, The AAM Press, Washington, DC, USA

Houghton, B (1988) “Not Just an Berkshire Farmer” Houghton, Newbury, Berkshire, UK

Houghton, B (1991) "Just more of the Berkshire Farmer" Houghton, Newbury, Berkshire, UK

Koushik M., Lee E.J., Pieroni L; Sun E; Yeh C.W. (2010) "Re-envisioning the Museum Experience: Combining New Technology with Social-Networking" In Yang, HS; Malaka, R; Hoshino, J; Han, JH (Eds.) Entertainment Computing - ICEC 2010, Vol. 6243, pp. 248-253

Proctor, N. (Ed.) (2011) “Mobile Apps for Museums”, The AAM Press, Washington, DC, USA

Williams P, Hanson-Baldauf D (2010) "Testing a Web information portal for people with learning disabilities" Journal of Research in Special Educational Needs Vol. 10 No. 1, pp. 42-51

Williams P, Nicholas D (2006) "Testing the usability of information technology applications with learners with special educational needs" Journal of Research in Special Educational Needs Vol. 6 No. 1, pp. 31-41

Williams, P (2012) "Web site usability testing involving people with learning disabilities using only images and audio to access information" Journal of Research in Special Educational Needs (in-press)

van Zeggeren D. (2011) "Connecting digital and physical worlds: Learnings from the IJdijken project" paper presented at Museum Computer Network Conference (MCN11), Atlanta, GA, USA 16-19 November 2011

i Note: some symbols used are Widgit Symbols (C) Widgit software 2002-20012 http://www.widgit.com ii as reported to Annette Haworth verbally by one of the museum staff. The audio system formed part of the "RNIB PenFriend at MShed by Bristol Museums Galleries \& Archives" project. See:

http://www.jodiawards.org.uk/awards-listing?item=132\&itemoffset=3 